\title{
Resection margins and local recurrences in breast cancer: Comparison between conventional and oncoplastic breast conserving surgery
}

\author{
Laura Niinikoski ${ }^{\text {a, }}{ }^{*}$, Marjut H.K. Leidenius ${ }^{a}$, Päivi Vaara ${ }^{a}$, Aleksandar Voynov ${ }^{\text {a }}$, \\ Päivi Heikkilä ${ }^{b}$, Johanna Mattson ${ }^{c}$, Tuomo J. Meretoja ${ }^{a}$ \\ a Breast Surgery Unit, Comprehensive Cancer Center, University of Helsinki, Helsinki University Hospital Finland, P.O. Box 263, 00029, HUS, Finland \\ ${ }^{\mathrm{b}}$ Department of Pathology, University of Helsinki, Helsinki University Hospital Finland, P.O. Box 400, 00029, HUS, Finland \\ ${ }^{\mathrm{c}}$ Comprehensive Cancer Center, University of Helsinki, Helsinki University Hospital Finland, PO Box 180, 00029, HUS, Finland
}

\section{A R T I C L E I N F O}

\section{Article history:}

Received 2 November 2018

Received in revised form

11 January 2019

Accepted 6 February 2019

Available online $\mathrm{xxx}$

\section{Keywords:}

Breast cancer

Breast conserving surgery

Surgical margins

Reoperations

Local recurrence

\begin{abstract}
A B S T R A C T
Background: This retrospective cohort study aims to compare surgical margins, reoperations and local recurrences after conventional or oncoplastic breast conservation surgery (BCS). Furthermore, we aim to investigate differences between various oncoplastic techniques.

Material and methods: We reviewed 1800 consecutive patients with primary invasive breast cancer $(\mathrm{N}=1707)$ or ductal carcinoma in situ $(\mathrm{N}=93)$ who underwent BCS at Helsinki University Hospital between 2010 and 2012.

Results: Conventional BCS was performed in 1189 (66.1\%) patients, oncoplastic BCS in 611 (33.9\%). Various oncoplastic techniques were used. Patients with oncoplastic BCS had more often multifocal $(\mathrm{p}<0.001)$, larger $(\mathrm{p}<0.001)$, palpable tumours $(\mathrm{p}<0.001)$ with larger resection specimens $(\mathrm{p}<0.001)$. The amount of resected tissue varied substantially depending on the oncoplastic technique. Patients treated with oncoplastic BCS were younger $(\mathrm{p}<0.001)$ and their tumours were more aggressive according to histological grade $(\mathrm{p}<0.001)$, T-stage $(\mathrm{p}<0.001)$, Ki-67 $(\mathrm{p}<0.001)$ and lymph node status $(\mathrm{p}<0.001)$.

There was no difference, however, in surgical margins $(p=0.578)$ or reoperation rates $(p=0.430)$ between the groups. A total of $152(8.4 \%)$ patients were reoperated because of insufficient margins, 96 $(8.1 \%)$ in the conventional, $56(9.2 \%)$ in the oncoplastic BCS group.

The median follow-up time was 75 (2-94) months. There was no difference in local recurrence-free survival between the conventional and oncoplastic BCS groups (log-rank test, $\mathrm{p}=0.172$ ).

Conclusions: Oncoplastic BCS was used for larger, multifocal and more aggressive tumours. Nevertheless, no difference in reoperation rate or local recurrences were found. Oncoplastic BCS is as safe as conventional BCS enabling breast conserving for patients who otherwise were candidates for mastectomy.

๑) 2019 Elsevier Ltd, BASO The Association for Cancer Surgery, and the European Society of Surgical
\end{abstract} Oncology. All rights reserved.

\section{Introduction}

Breast conserving surgery (BCS), instead of mastectomy, has long since established its role as the standard of surgical care in the treatment of early-stage breast cancer. Oncoplastic BCS techniques have further extended the possibilities of BCS into the treatment of larger and multifocal tumours as well as extensive ductal carcinoma in situ (DCIS), without compromising the oncological safety or aesthetic outcome [1]. Oncoplastic BCS allow resections of up to

\footnotetext{
* Corresponding author. Breast Surgery Unit, Comprehensive Cancer Center, P.O. Box 263, 00029, HUS, Finland.

E-mail address: laura.niinikoski@hus.fi (L. Niinikoski).
}

$50 \%$ of breast volume without causing deformity.

Adequate surgical margins are decisive in reducing the risk of local recurrence (LR) [2]. Positive surgical margins are generally thought to necessitate a reoperation, either a re-excision, or a mastectomy [3]. A second operation can cause discomfort and stress to the patient, lead to an increased risk of surgical complications and to poor aesthetic outcome, delay adjuvant therapy and increase health care costs [2,4-6]. Furthermore, the patients who undergo a re-excision may have an increased risk of developing LR, compared to patients with only one operation [7].

There are several studies reporting short- and even long-term outcomes after oncoplastic BCS, mainly after reduction mammoplasty techniques [3,8-12]. Oncoplastic BCS, however, includes 


\begin{tabular}{|ll|}
\hline \multicolumn{2}{|l|}{ Abbreviations } \\
BCS & Breast conserving surgery \\
DCIS & ductal carcinoma in situ \\
LR & local recurrence \\
RT & radiotherapy \\
CNB & core needle biopsy \\
FNAC & fine needle aspiration cytology \\
ROLL & radioguided occult lesion localization \\
MRI & magnetic resonance imaging \\
SNB & sentinel node biopsy \\
MDT & multidisciplinary team \\
CT & computed tomography scan \\
LRFS & local recurrence free survival \\
\hline
\end{tabular}

several different techniques [1], which differ substantially regarding the amount of resected tissue.

This retrospective cohort study aims to compare surgical margins, reoperations and LR after conventional or oncoplastic BCS. In addition, we aim to investigate differences between various oncoplastic BCS techniques.

\section{Patients and methods}

Consecutive patients with primary invasive breast cancer or DCIS who underwent BCS at Breast Surgery Unit of Helsinki University Hospital between the January 1st, 2010 and December 31st, 2012 were included in this retrospective cohort study. We excluded the patients who underwent merely a tumourectomy with neither adjuvant treatment nor axillary surgery due to comorbidities $(\mathrm{N}=29)$. In addition, we excluded the patients who had been diagnosed by surgical biopsy $(\mathrm{N}=45)$ and those whose breast cancer was found unexpectedly in reduction mammoplasty specimen $(\mathrm{N}=2)$. Remaining 1800 cases were categorized into two groups, conventional or oncoplastic BCS. None of the patients had received neoadjuvant treatment.

The data was collected from electronic patient records: patient and tumour characteristics, surgical technique, excision margins and specimen weight, re-excision rate, lymph node status, adjuvant systemic treatment, postoperative radiotherapy (RT), time to local, regional or distant recurrence, date and cause of death and date of last follow-up. Patients with bilateral cancer were regarded as two separate cases with possibly different BCS techniques.

\section{Imaging}

All patients underwent mammography as well as breast and axillary ultrasound. Core needle biopsy (CNB) was taken from breast lesion(s) and fine needle aspiration cytology (FNAC) from suspicious axillary lymph nodes. The patients who had an invasive lobular carcinoma diagnosed on CNB underwent magnetic resonance imaging (MRI) $(\mathrm{N}=270)$.

\section{Surgical technique}

All breast and axillary operations were performed or supervised by an experienced breast surgeon. Impalpable lesions were localized either with radioguided occult lesion localization (ROLL), hooked wire or radioactive seed. Surgeon had chosen the most suitable operation technique individually depending on the location and size of the tumour, as well as on the size and the glandular density of breast, in agreement with the patient. In this study, conventional BCS stands for resection of the tumour with adequate mobilization and closure of breast tissue. Oncoplastic BCS instead refers to other level 1 and level 2 oncoplastic procedures [1].

The patients who had been diagnosed with axillary lymph node metastasis in ultrasound guided FNAC underwent axillary lymph node dissection. Sentinel node biopsy (SNB) was performed in patients with invasive breast cancer, node negative in axillary ultrasound. The patients with DCIS but a suspicion of invasion in CNB underwent SNB likewise.

Reoperation due to inadequate margins was either a re-excision or a mastectomy depending on breast size, glandular density and aesthetic result after the first operation, with patient's preference taken into account. The guidelines for adequate surgical margins changed at the beginning of the study period in 2010 and new recommendations were adopted in our unit gradually. Previously $5 \mathrm{~mm}$ microscopical histological margins were required for invasive cancer and $10 \mathrm{~mm}$ for DCIS. Consensus symposium in $2010 \mathrm{rec}-$ ommended that no ink on tumour is adequate for invasive cancer and $2 \mathrm{~mm}$ for DCIS with or without concomitant invasive tumour [13].

\section{Histopathological examination}

Histopathological analyses from surgical specimens were performed by experienced breast pathologists. The breast and lymph node specimens were handled and examined as described in our earlier study [14].

\section{Adjuvant treatment}

All cases were discussed at a multidisciplinary team (MDT) meeting after surgery in order to recommend adjuvant treatments. All patients received postoperative RT except those who underwent mastectomy as a second operation and those whose general condition was not suitable for RT. The patients who had distant metastasis identified on postoperative whole body computed tomography scan (CT) did not receive RT either. Adjuvant chemotherapy and endocrine treatment were recommended according to the Finnish national evidence-based guidelines [15]. The patients with DCIS or with luminal T1a-b invasive, node negative breast cancer do not receive adjuvant systemic treatment. The RT and adjuvant systemic treatment protocols used at our institution are described in our earlier study [16].

\section{Follow-up}

The first clinical checkup took place within three weeks after the operation. After adjuvant chemotherapy and/or radiotherapy the patients were followed-up for five years. Very young women and women with hereditary breast cancer were followed-up for ten years at the Department of Oncology of Helsinki University Hospital. The follow-up consisted of visits at one, three and five years after the operation. In addition, a phone service operated by a breast cancer nurse practitioner was available for patients who needed counselling about symptoms related to side-effects of treatments or potential recurrence. The patients had a possibility for further visits if needed.

Mammography was performed yearly and combined with ultrasound in women $\leq 45$ years or older with high density of breast in mammography or if needed as further diagnostic investigation. Annual MRI of the breasts was performed in women with high risk hereditary breast cancer. Additionally, MRI, whole body CT or bone isotope scan were done whenever indicated for instance due to symptoms which might indicate local or distant recurrence.

After the first five years or in some patients after ten years the 
follow-up continued at primary health care.

\section{Statistics}

Statistical analyses were performed using IBM $^{\text {тм }}$ SPSS ${ }^{\mathrm{TM}}$ Statistics version 22 software (SPSS Inc., Chicago, IL). Frequency tables were analyzed with chi-squared test and continuous distributions with Mann-Whitney $U$ test.

For LR survival analysis and for other breast cancer events, we excluded the patients with bilateral disease $(\mathrm{N}=87)$, earlier breast cancer $(\mathrm{N}=69)$, other malignancy within five years (apart from DCIS or basal cell carcinoma, $\mathrm{N}=105$ ), distant metastasis diagnosed within 12 months after primary operation $(\mathrm{N}=18)$ and those who underwent a completion mastectomy $(\mathrm{N}=80)$. In addition, we excluded the patients who were followed-up for less than three years due to relocation to other hospital district $(N=30)$. The remaining 1411 patients went through a Kaplan-Meier survival analysis for local recurrence-free survival (LRFS), the conventional and oncoplastic BCS groups were compared with the log-rank test. Other breast cancer events were assessed with Fisher's exact test simply comparing event counts.

This retrospective study did not require an ethics committee permission, but was approved by the institutional research board of Helsinki University Hospital.

\section{Results}

The patient and tumour characteristics are summarized in Table 1.1707 patients had invasive breast cancer and 93 had DCIS. Conventional BCS was performed in 1189 patients (66.1\%) and

Table 1

Patient and tumour characteristics for conventional and oncoplastic breast conserving surgery.

\begin{tabular}{|c|c|c|c|c|c|c|}
\hline & & \multicolumn{2}{|c|}{ Conventional BCS N=1189 } & \multicolumn{2}{|c|}{ Oncoplastic BCS N = 611} & \multirow[t]{2}{*}{ p-value } \\
\hline & & $\mathrm{N}$ & $\%$ & $\mathrm{~N}$ & $\%$ & \\
\hline \multirow[t]{2}{*}{ Tumour } & Impalpable & 750 & $63.1 \%$ & 255 & $41.7 \%$ & \multirow[t]{2}{*}{$<0.001$} \\
\hline & Palpable & 439 & $36.9 \%$ & 356 & $58.3 \%$ & \\
\hline Reoperation due to & No & 1093 & $91.9 \%$ & 555 & $90.8 \%$ & \multirow[t]{2}{*}{0.430} \\
\hline insufficient margins & Yes & 96 & $8.1 \%$ & 56 & $9.2 \%$ & \\
\hline \multirow[t]{2}{*}{ Reoperation } & Re-excision & 42 & $43.8 \%$ & 17 & $30.4 \%$ & \multirow[t]{2}{*}{0.102} \\
\hline & Mastectomy & 54 & $56.3 \%$ & 39 & $69.6 \%$ & \\
\hline \multirow[t]{4}{*}{ Histology } & DCIS & 64 & $5.4 \%$ & 29 & $4.7 \%$ & \multirow[t]{4}{*}{0.877} \\
\hline & Invasive ductal carcinoma & 826 & $69.5 \%$ & 424 & $69.4 \%$ & \\
\hline & Invasive lobular carcinoma & 136 & $11.4 \%$ & 76 & $12.4 \%$ & \\
\hline & Other invasive & 163 & $13.7 \%$ & 82 & $13.4 \%$ & \\
\hline \multirow[t]{5}{*}{ Pathological T stage } & pTis & 64 & $5.4 \%$ & 28 & $4.6 \%$ & \multirow[t]{5}{*}{$<0.001$} \\
\hline & pT1 & 990 & $83.3 \%$ & 415 & $67.9 \%$ & \\
\hline & pT2 & 132 & $11.1 \%$ & 164 & $26.8 \%$ & \\
\hline & pT3 & 2 & $0.2 \%$ & 3 & $0.5 \%$ & \\
\hline & pT4 & 1 & $0.1 \%$ & 1 & $0.2 \%$ & \\
\hline \multirow{2}{*}{ Multifocal tumour } & No & 1066 & $89.7 \%$ & 512 & $83.8 \%$ & \multirow[t]{2}{*}{$<0.001$} \\
\hline & Yes & 123 & $10.3 \%$ & 99 & $16.2 \%$ & \\
\hline \multirow[t]{2}{*}{ EIC } & 0 & 1077 & $90.6 \%$ & 538 & $88.1 \%$ & \multirow[t]{2}{*}{0.094} \\
\hline & 1 & 112 & $9.4 \%$ & 73 & $11.9 \%$ & \\
\hline \multirow[t]{4}{*}{ Tumour grade } & 1 & 416 & $35.0 \%$ & 175 & $28.6 \%$ & \multirow[t]{4}{*}{$<0.001$} \\
\hline & 2 & 500 & $42.1 \%$ & 237 & $38.8 \%$ & \\
\hline & 3 & 272 & $22.9 \%$ & 198 & $32.4 \%$ & \\
\hline & NA & 1 & $0.1 \%$ & 1 & $0.2 \%$ & \\
\hline \multirow[t]{3}{*}{ ER } & Negative & 100 & $8.4 \%$ & 68 & $11.1 \%$ & \multirow[t]{3}{*}{0.171} \\
\hline & Positive & 1028 & $86.5 \%$ & 512 & $83.8 \%$ & \\
\hline & NA & 61 & $5.1 \%$ & 31 & $5.1 \%$ & \\
\hline PR & Negative & 303 & $25.5 \%$ & 184 & $30.1 \%$ & 0.108 \\
\hline & Positive & 825 & $69.4 \%$ & 396 & $64.8 \%$ & \\
\hline & NA & 61 & $5.1 \%$ & 31 & $5.1 \%$ & \\
\hline Ki-67 & $0-15 \%$ & 680 & $57.4 \%$ & 291 & $47.6 \%$ & $<0.001$ \\
\hline & $16-30 \%$ & 260 & $22.0 \%$ & 155 & $25.4 \%$ & \\
\hline & $>30 \%$ & 183 & $15.5 \%$ & 134 & $21.9 \%$ & \\
\hline & NA & 61 & $5.1 \%$ & 31 & $5.1 \%$ & \\
\hline HER & Negative & 1032 & $86.8 \%$ & 505 & $82.6 \%$ & 0.016 \\
\hline & Positive & 96 & $8.1 \%$ & 75 & $12.3 \%$ & \\
\hline & NA & 61 & $5.1 \%$ & 31 & $5.1 \%$ & \\
\hline Lymph node status & pNO & 891 & $74.9 \%$ & 415 & $67.9 \%$ & $<0.001$ \\
\hline & pN1mic & 85 & $7.1 \%$ & 36 & $5.9 \%$ & \\
\hline & $\mathrm{pN} 1 \mathrm{mac}$ & 213 & $17.9 \%$ & 160 & $26.2 \%$ & \\
\hline Radiotherapy & No & 63 & $5.3 \%$ & 31 & $5.1 \%$ & 0.839 \\
\hline & Yes & 1126 & $94.7 \%$ & 580 & $94.9 \%$ & \\
\hline Adjuvant treatment & No & 317 & $26.7 \%$ & 85 & $13.9 \%$ & $<0.001$ \\
\hline & Endocrine treatment & 512 & $43.1 \%$ & 234 & $38.3 \%$ & \\
\hline & Chemotherapy & 61 & $5.1 \%$ & 62 & $10.1 \%$ & \\
\hline & Both & 299 & $25.1 \%$ & 230 & $37.6 \%$ & \\
\hline & Median (range) & Median (range) & & & & \\
\hline Age (years) & $62(35-93)$ & $61(37-86)$ & $<0.001$ & & & \\
\hline Tumour size (mm) & $12(1-86)$ & $16(1-80)$ & $<0.001$ & & & \\
\hline Smallest lateral surgical margin (mm) & $10(0-40)$ & $10(0-56)$ & 0.578 & & & \\
\hline Specimen weight $(\mathrm{g})$ & $56(8-507)$ & $77(10-1893)$ & $<0.001$ & & & \\
\hline
\end{tabular}

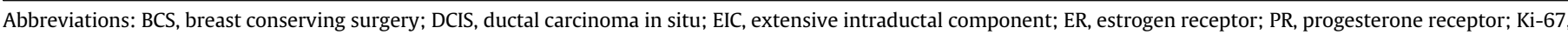
proliferation marker; HER, Human Epidermal Growth Factor Receptor; NA, Not available. 
oncoplastic BCS in 611 (33.9\%). Various oncoplastic techniques were used, these are provided in Table 3. The percentage of patients with pure DCIS was similar in conventional BCS group (5.4\%) and in oncoplastic BCS group (4.7\%) ( $\mathrm{p}=0.877)$.

Patients with oncoplastic BCS had more often multifocal $(\mathrm{p}<0.001)$, larger $(\mathrm{p}<0.001)$, and palpable tumours $(\mathrm{p}<0.001)$ with larger resection specimens $(\mathrm{p}<0.001)$. The amount of resected tissue varied substantially depending on the oncoplastic technique. Median specimen weight was $56 \mathrm{~g}$ in conventional BCS group and $77 \mathrm{~g}$ in oncoplastic group $(\mathrm{p}<0.001)$. The range of specimen weight was wide in the oncoplastic group (10-1893 g).

Patients treated with oncoplastic BCS were slightly younger $(\mathrm{p}<0.001)$ and their tumours were more aggressive according to histological grade $(\mathrm{p}<0.001)$, T-stage $(\mathrm{p}<0.001)$, Ki-67 proliferation index $(\mathrm{p}<0.001)$ and lymph node status $(\mathrm{p}<0.001)$.

\section{Reoperations}

There was no difference, however, in surgical margins $(p=0.578)$ or reoperation rates $(p=0.430)$ between the groups (Table 2). A total of 152 (8.4\%) patients were reoperated because of insufficient margins, 96 (8.1\%) in the conventional BCS group and $56(9.2 \%)$ in the oncoplastic BCS group.

Risk factors for reoperations were multifocality of the tumour $(\mathrm{p}<0.001)$, larger tumour size and high pathological T-stage $(\mathrm{p}<0.001)$ and extensive intraductal component (EIC) $(\mathrm{p}<0.001)$.

Of 222 patients with multifocal tumours $67(30.2 \%)$ underwent a reoperation, compared to 85 out of 1578 (5.4\%) patients with unifocal tumours. The median size of the tumours, in patients undergoing a reoperation, was $16 \mathrm{~mm}(1-80 \mathrm{~mm})$. Of 185 patients with EIC, $37(20.0 \%)$ underwent a reoperation compared to $115(7.1 \%)$ of 1615 without EIC.

Table 2

Patient and tumour characteristics for reoperations due to inadequate margins.

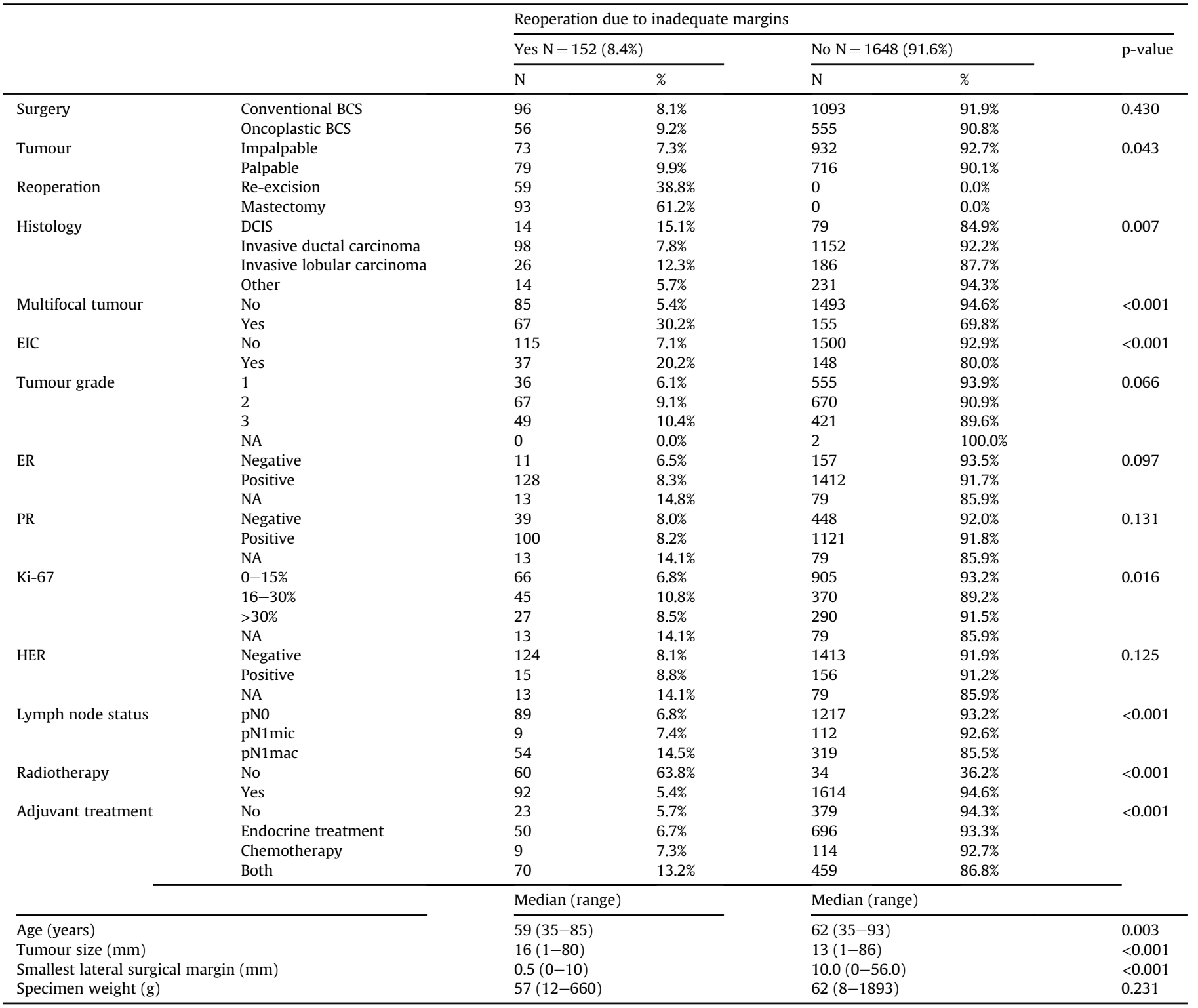

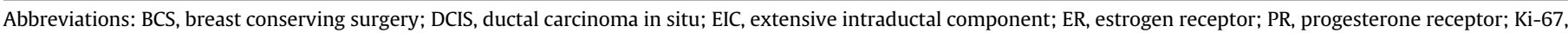
proliferation marker; HER, Human Epidermal Growth Factor Receptor; NA, Not available. 
After oncoplastic BCS, reoperation seemed to be more often mastectomy (69.6\%) compared to conventional BCS group (56.3\%), but the difference was not statistically significant $(p=0.102)$.

\section{Oncoplastic BCS techniques}

Eleven different oncoplastic BCS techniques were used (Table 3). Racket mammoplasty (30.1\%) and round block (28.0\%) were the most common methods. Only 55 patients were operated using reduction mammoplasty techniques, superior or inferior pedicle mammoplasty or wise-pattern reduction with resection of nippleareolar complex (wise-amputation). The reoperation rate ranged from $5.0 \%$ (J-mammoplasty) to $29.4 \%$ (batwing mammoplasty), but was similar in the most of the groups $(7.7-10 \%)$. The number of batwing-mammoplasty procedures $(\mathrm{N}=17)$ was small in this series.

\section{Breast cancer recurrence}

Altogether 1411 patients remained for survival analysis of LRFS, 940 in the conventional group and 471 in the oncoplastic BCS group (Table 4). The median follow-up time was 75 (2-94) months. There was no difference in LRFS between the conventional and oncoplastic BCS groups in the Kaplan-Meier analysis (log-rank test, $\mathrm{p}=0.172$, Fig. 1). The five-year LRF survival estimates for conventional and oncoplastic BCS groups were $98.0 \%$ and $98.9 \%$, respectively.

Contralateral breast cancer recurrence and regional lymph node recurrences are summarized in Table 4. Distant metastases were detected in 29 (3.1\%) patients in the conventional BCS group and in $16(3.4 \%)$ patients in the oncoplastic BCS group (Fisher's test, $\mathrm{p}=0.750)$. Eight of the $32(25.0 \%)$ patients with ipsilateral LR developed distant metastasis as well. Six of them were diagnosed with ipsilateral LR concomitantly with distant disease, one had ipsilateral LR as a primary event and one distant metastasis first.

In total, 73 patients died during the follow-up, $56(6.0 \%)$ in the conventional BCS group and 17 (3.6\%) in the oncoplastic BCS group (Fisher's test, $\mathrm{p}=0.074)$. Eighteen $(1.9 \%)$ patients in the conventional group and seven (1.5\%) in the oncoplastic BCS group died from breast cancer (Fisher's test, $\mathrm{p}=0.672$ ).

\section{Discussion}

\section{Main message}

Our study indicates that oncoplastic BCS is as safe as conventional BCS even though oncoplastic techniques were used for larger, multifocal and more aggressive tumours. We found no difference in surgical margins, reoperation rates nor LR rates between the groups.

In this study, we wanted to put a special focus on evaluating results between different oncoplastic techniques. The concept of oncoplastic BCS includes a broad range of varying surgical techniques; some techniques are appropriate for small sized tumours and breasts and others for multifocal and large tumours or for large breasts. There are many studies assessing results after oncoplastic reduction mammoplasty surgery, but only few reports on other oncoplastic BCS techniques.

\section{Resection margins and reoperations}

In our series, reoperation rate was low (8.4\%). Tumour size, multifocal disease and EIC proved to be predictors of inadequate margins. This is consistent with several other previous studies [8,17-19]. A trend towards a higher risk of reoperation in the DCIS group (15.1\%) and in the invasive lobular carcinoma group (12.3\%) was observed, as reported earlier [8,11,20], yet this did not reach statistical significance $(\mathrm{p}=0.007)$.

The reoperation rate after oncoplastic BCS was $9.2 \%$ and it was similar in most of the oncoplastic BCS groups, although the amount of resected tissue ranged considerably. We decided not to compare each oncoplastic BCS technique statistically against each other, as the number of patients in many of the groups is very small.

The positive margin rate in our study is comparable to the rates reported earlier in the studies of oncoplastic BCS by Clough et al. (12.6\%) [8], De La Cruz et al. (10.8\%) [3], Hillberg et al. (9.3\%) [10], Romics et al. (10.4\%) [11] and Losken et al. (12.3\%) [12]. Rietjens et al. [9] reported a lower positive margin rate (5.4\%) and Wijgman et al. a higher rate (22.6\%) [20] compared to our study. In all of these studies the margins were heterogeneously classified and not analyzed according to different oncoplastic techniques. On the other hand, the tumours were larger in diameter in most of these studies $(15-27 \mathrm{~mm}$ ) compared to our results.

The median specimen weight in our series was $77 \mathrm{~g}$. Not surprisingly, it was highest in patients with reduction mammoplasty techniques. The lowest median specimen weight resulted after round block, J-mammoplasty and batwing techniques. The specimen weights in previous studies were often higher $(168-249 \mathrm{~g})$. They reported, however, mainly breast reduction and flap techniques $[3,8,9,12]$.

In cases of inadequate surgical margins, the reoperation was more often a completion mastectomy in the oncoplastic BCS group than in the conventional BCS group. Oncoplastic technique was chosen primarily for larger or multifocal tumour in order to avoid mastectomy. After the oncoplastic BCS a re-excision might have compromised the aesthetic result. Thus, mastectomy was performed more often as the second procedure in the oncoplastic BCS group.

Table 3

Oncoplastic breast conserving surgery techniques.

\begin{tabular}{|c|c|c|c|c|}
\hline & \multirow[t]{2}{*}{$\mathrm{N}$} & \multirow{2}{*}{$\frac{\text { Smallest lateral surgical margin }(\mathrm{mm})}{\text { Median (range) }}$} & \multirow{2}{*}{$\frac{\text { Specimen weight }(\mathrm{g})}{\text { Median (range) }}$} & \multirow{2}{*}{$\frac{\text { Reoperation due to insufficient margins }}{\mathrm{N}(\%)}$} \\
\hline & & & & \\
\hline Racket & 184 & $10.0(0-45.0)$ & $80(15-707)$ & $18(9.8)$ \\
\hline Round block & 171 & $10.0(0-30.0)$ & $54(10-183)$ & $14(8.2)$ \\
\hline Upper rotation & 67 & $10.0(0-30.0)$ & $121(23-392)$ & $6(9.0)$ \\
\hline Lower rotation & 50 & $10.0(0-20.0)$ & $66(28-726)$ & $4(8.0)$ \\
\hline Superior pedicle & 37 & $12.0(0-35.0)$ & $331(12-1180)$ & $3(8.1)$ \\
\hline inferior pedicle & 10 & $14.0(2.0-20.0)$ & $495(168-1546)$ & $1(10)$ \\
\hline Mastopexy & 26 & $7.5(1.0-30.0)$ & $80(16-256)$ & $2(7.7)$ \\
\hline S-plasty & 21 & $10.0(0-56.0)$ & $538(44-1255)$ & $2(9.5)$ \\
\hline J-plasty & 20 & $12.5(0.3-30.0)$ & $55(24-312)$ & $1(5.0)$ \\
\hline Batwing & 17 & $5.0(0-15.0)$ & $58(18-288)$ & $5(29.4)$ \\
\hline Wise-amputation & 8 & $26.5(9.0-50.0)$ & $1604(110-1893)$ & $0(0)$ \\
\hline
\end{tabular}


Table 4

Breast cancer events observed during follow-up.

\begin{tabular}{|c|c|c|c|}
\hline \multirow[t]{2}{*}{ Event } & \multirow{2}{*}{$\frac{\text { Conventional BCS }(\mathrm{N}=940)}{\mathrm{N}(\%)}$} & \multirow{2}{*}{$\frac{\text { Oncoplastic BCS }(\mathrm{N}=471)}{\mathrm{N}(\%)}$} & \multirow[t]{2}{*}{ p-value (Fisher) } \\
\hline & & & \\
\hline Ipsilateral breast recurrence & $25(2.7 \%)$ & $7(1.5 \%)$ & 0.188 \\
\hline Contralateral breast recurrence & $12(1.3 \%)$ & $4(0.8 \%)$ & 0.599 \\
\hline Regional lymph node recurrence & $10(1.1 \%)$ & $3(0.6 \%)$ & 0.562 \\
\hline Ipsilateral axilla ${ }^{\mathrm{a}}$ & $4(0.4 \%)$ & $2(0.4 \%)$ & \\
\hline Contralateral axilla ${ }^{\mathrm{b}}$ & $2(0.2 \%)$ & 0 & \\
\hline Supraclavicular node & $4(0.4 \%)$ & $1(0.2 \%)$ & \\
\hline Distant metastasis ${ }^{c}$ & $29(3.1 \%)$ & $16(3.4 \%)$ & 0.750 \\
\hline Death from breast cancer & $18(1.9 \%)$ & $7(1.5 \%)$ & 0.672 \\
\hline Death from any cause & $56(6.0 \%)$ & $17(3.6 \%)$ & 0.074 \\
\hline
\end{tabular}

a Five patients had concomitant LR.

b Both of the patients had concomitant LR.

c Eight patients had ipsilateral LR concomitantly with distant disease, one had ipsilateral LR as a primary event and distant metastasis later, one had distant metastasis first and LR later.

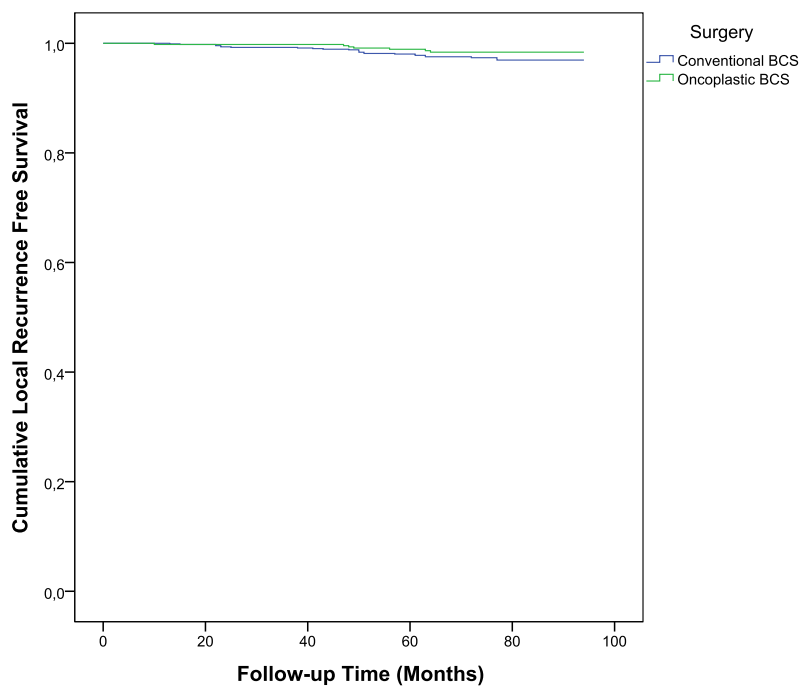

Fig. 1. Kaplan-Meier survival analysis for local recurrence-free survival after conventional and oncoplastic breast conserving surgery.

Waiting time for adjuvant treatment is discussed in our previous study, which included patients who underwent BCS in 2010 at our institution [21]. There was no difference in median waiting time between conventional and oncoplastic surgery ( 47 vs. 48 days).

\section{Local recurrences}

In our study, the ipsilateral LR rate during a median of 75 months follow-up was $2.3 \%$. This is comparable to other studies. Romics et al. [11] reported a LR rate of $2.7 \%$ during a median of 30 months follow-up, Clough et al. a LR rate of $2.2 \%$ during a median of 55 months follow-up [8] and Rietjens at al. [9] a LR of 3.4\% during a median of 74 months follow-up. In a systematic literature review [3] the LR rate was $3.2 \%$ during a mean of 50.5 months follow-up and $6.0 \%$ if the follow-up was more than five years. Contralateral breast cancer recurrences and regional lymph node recurrences were rare in our series.

\section{Strengths and limitations of the study}

Our study examined a large number of patients and it was carried out in a single institution. Our examination and treatment protocols including surgical practice are standardized. We report here several different oncoplastic techniques, both level 1 and level 2 , not merely oncoplastic reduction mammoplasty techniques. Thereby, our study displays the entire spectrum of various oncoplastic techniques used in our center in real-life clinical practice and in an unselected cohort of breast cancer patients.

Limitation of this study is the retrospective design. The guidelines for adequate surgical margins changed at the beginning of year 2010 and the new margin recommendation 'no ink on tumour' was adopted gradually, therefore the indication for reoperation is not standard throughout the study period. Furthermore, the indications for reoperations are not similar in different units, which hinders the comparison with other studies.

We did not assess the aesthetic outcome of BCS in this study, as it is reported in our earlier study [22]. We did not record postoperative complications either.

\section{Conclusion}

Oncoplastic BCS was used for larger, multifocal and more aggressive tumours. Nevertheless, no difference in reoperation rate or LR rate were found. Oncoplastic BCS is as safe as conventional BCS enabling breast conserving for patients who otherwise were candidates for mastectomy.

\section{Declaration of interest}

All authors decline any conflict of interest regarding to the specific topic of this article.

\section{Funding}

The corresponding author was supported by research funds of the Helsinki University Hospital.

\section{References}

[1] Clough KB, Kaufman GJ, Nos C, et al. Improving breast cancer surgery: a classification and quadrant per quadrant atlas for oncoplastic surgery. Ann Surg Oncol 2010 May;17(5):1375-91.

[2] Behm EC, Beckmann KR, Dahlstrom JE, et al. Surgical margins and risk of locoregional recurrence in invasive breast cancer: an analysis of 10-year data from the Breast Cancer Treatment Quality Assurance Project. Breast 2013 Oct;22(5):839-44.

[3] De La Cruz L, Blankenship SA, Chatterjee A, et al. Outcomes after oncoplastic breast-conserving surgery in breast cancer patients: a systematic literature review. Ann Surg Oncol 2016 Oct;23(10):3247-58.

[4] Yu KD, Huang S, Zhang JX, et al. Association between delayed initiation of adjuvant CMF or anthracycline-based chemotherapy and survival in breast cancer: a systematic review and meta-analysis. BMC Canc 2013 May 16;13: 240. 
[5] Chen Z, King W, Pearcey R, et al. The relationship between waiting time for radiotherapy and clinical outcomes: a systematic review of the literature. Radiother Oncol 2008 Apr;87(1):3-16.

[6] Moran MS, Schnitt SJ, Giuliano AE, et al. Society of Surgical Oncology-American Society for Radiation Oncology consensus guideline on margins for breast-conserving surgery with whole-breast irradiation in stages I and Il invasive breast cancer. Int J Radiat Oncol Biol Phys 2014 Mar 1;88(3):553-64.

[7] Hennings A, Fuchs V, Sinn HP, et al. Do patients after reexcision due to involved or close margins have the same risk of local recurrence as those after one-step breast-conserving surgery? Ann Surg Oncol 2016 Jun;23(6):1831-7.

[8] Clough KB, van la Parra RFD, Thygesen HH, et al. Long-term results after oncoplastic surgery for breast cancer: a 10-year follow-up. Ann Surg 2018 Jul;268(1):165-71.

[9] Rietjens M, Urban CA, Rey PC, et al. Long-term oncological results of breast conservative treatment with oncoplastic surgery. Breast 2007 Aug;16(4): 387-95.

[10] Hillberg NS, Meesters-Caberg MAJ, Beugels J, et al. Delay of adjuvant radiotherapy due to postoperative complications after oncoplastic breast conserving surgery. Breast 2018 Jun;39:110-6.

[11] Romics L, Macaskill EJ, Fernandez T, et al. A population-based audit of surgical practice and outcomes of oncoplastic breast conservations in Scotland - an analysis of 589 patients. Eur J Surg Oncol 2018 Jul;44(7):939-44.

[12] Losken A, Dugal CS, Styblo TM, Carlson GW. A meta-analysis comparing breast conservation therapy alone to the oncoplastic technique. Ann Plast Surg 2014 Feb;72(2):145-9.

[13] Kaufmann M, Morrow M, von Minckwitz G, et al. Locoregional treatment of primary breast cancer: consensus recommendations from an International Expert Panel. Cancer 2010 Mar 1;116(5):1184-91.

[14] Leidenius MH, Vironen JH, Heikkilä PS, Joensuu H. Influence of isolated tumor cells in sentinel nodes on outcome in small, node-negative (pT1N0M0) breast cancer. Ann Surg Oncol 2010 Jan;17(1):254-62.

[15] Finnish Breast Cancer Group. Rintasyövän valtakunnallinen diagnostiikka- ja hoitosuositus. 2018. updated 6/2018, https://rintasyoparyhma.yhdistysavain. fi/@Bin/181912/Rintasy\%C3\%B6v\%C3\%A4n\%20valtakunnallinen\%20diagnostiikka\%20ja\%20hoitosuositus\%206.2018.pdf.

[16] Liikanen J, Leidenius M, Joensuu H, et al. Breast cancer prognosis and isolated tumor cell findings in axillary lymph nodes after core needle biopsy and fine needle aspiration cytology: biopsy method and breast cancer outcome. Eur J Surg Oncol 2016 Jan;42(1):64-70.

[17] Sanchez C, Brem RF, McSwain AP, et al. Factors associated with re-excision in patients with early-stage breast cancer treated with breast conservation therapy. Am Surg 2010 Mar;76(3):331-4.

[18] Jeevan R, Cromwell DA, Trivella M, et al. Reoperation rates after breast conserving surgery for breast cancer among women in England: retrospective study of hospital episode statistics. BMJ 2012 Jul 12;345:e4505.

[19] Valero MG, Mallory MA, Losk K, et al. Surgeon variability and factors predicting for reoperation following breast-conserving surgery. Ann Surg Oncol. 2018 Sep;25(9):2573-8.

[20] Wijgman DJ, Ten Wolde B, van Groesen NR, et al. Short term safety of oncoplastic breast conserving surgery for larger tumors. Eur J Surg Oncol. 2017 Apr;43(4):665-71.

[21] Ojala K, Meretoja TJ, Mattson J. The quality of preoperative diagnostics and surgery and their impact on delays in breast cancer treatment - a population based study. Breast 2016 Apr;26:80-6. https://doi.org/10.1016/j.breast. 2015.12.009. Epub 2016 Feb 1

[22] Ojala K, Meretoja TJ, Leidenius MH. Aesthetic and functional outcome after breast conserving surgery - comparison between conventional and oncoplastic resection. Eur J Surg Oncol. 2017 Apr;43(4):658-64. 